\title{
Twaalf tips voor computerondersteund toetsen in het medisch onderwijs*
}

\author{
W.P.M. Hols-Elders, P.M. Bloemendaal, N.R. Bos, M.J. Quaak, R. Sijstermans, P.G.M. de Jong
}

\section{Samenvatting}

Het gebruik van computers in het onderwijs in het algemeen, en in het medisch onderwijs in het bijzonder, is vandaag de dag gemeengoed geworden. De toepassing van digitaal toetsen blijft echter binnen het medisch onderwijs flink achter op de ontwikkelingen in het hoger onderwijs. In dit artikel beschrijven we enkele oorzaken voor deze situatie en verschaffen we een twaalftal tips voor docenten en opleidingsbestuurders om hen te begeleiden bij de introductie van digitaal toetsen. Dit alles is gebaseerd op de ervaringen van de auteurs, tevens lid van de NVMO-werkgroep E-learning. Er wordt aandacht besteed aan voor-en nadelen van digitaal toetsen, aan hardware oplossingen, aan de keuze van software en soorten toetsvragen, aan het instrueren van studenten en docenten en aan het evalueren van toetsen. (Hols-Elders WPM, Bloemendaal PM, Bos NR, Quaak MJ, Sijstermans R, Jong PGM de. Twaalf tips voor computerondersteund toetsen in het medisch onderwijs. Tijdschrift voor Medisch Onderwijs 2009;28(1):4-12.)

\section{Inleiding}

Net zoals in het hoger onderwijs is sinds enkele jaren het gebruik van computers gemeengoed geworden voor diverse toepassingen zoals zelfstudie, klassikaal leren en andere settings. ${ }^{1-2}$ Het tijdperk van het geschreven boek transformeert zo langzamerhand naar een tijdperk van digitale media. Het gebruik van digitale toetsmogelijkheden blijft alleen nog ver achter. Bij de meeste medische faculteiten zijn schriftelijke toetsen nog steeds gemeengoed en soms zelfs de enige vorm van kennistoetsing, terwijl computerondersteund toetsen (COT) toch duidelijk voordelen kan bieden. ${ }^{3-7}$ COT biedt niet alleen nieuwe mogelijkheden voor tijd- en plaatsonafhankelijk toetsen, maar ook voor het betekenisvol rangschikken van vragen, voor het werken met geluiden en met plaatjes (zowel stilstaand als bewegend), voor het aanpassen van de toets op de voorgaande prestaties van de student, voor het snel berekenen van scores en voor het geven van feedback op maat aan elke individuele student. Zelfs communicatievaardigheden kunnen getoetst worden met de computer. ${ }^{8-10}$ Over het algemeen waarderen studenten de inzet van COT. ${ }^{11-14}$ Het gebruik van computers voor toetsing is inherent aan het automatiseren van de processen rondom toetsafname; het kan bijdragen aan een reductie van administratieve en tijdrovende processen, terwijl het tegelijkertijd mogelijkheden biedt de toetskwaliteit te laten toenemen. ${ }^{14-16}$

In Nederland wordt COT nog maar op zeer beperkte schaal in de bachelorfase van het medisch onderwijs voor summatieve doeleinden toegepast. We hebben de indruk dat dit voor meer landen in onze directe omgeving geldt. Er kunnen ver-

\footnotetext{
* Dit artikel verscheen eerder onder de oorspronkelijke titel: Hols-Elders W, Bloemendaal P, Bos N, Quaak M, Sijstermans R. Jong P de. Twelve tips for computer-based assessment in medical education. Med Teach 2008;30(3).
} 
schillende oorzaken zijn voor deze situatie, zoals het gebrek aan technische kennis en vaardigheden bij docenten in het medisch onderwijs om COT te ontwikkelen, het ontbreken van zowel tijd als het gevoel van noodzaak dit te bereiken en het gebrek aan middelen en computerfaciliteiten om COT uit te voeren.

Met de volgende twaalf tips willen wij inzicht geven in onze ervaringen op het gebied van COT. Wij willen echter niet suggereren dat het transformeren van schriftelijke toetsen naar COT gemakkelijk is, zeker niet bij grote studentenaantallen. In tegendeel, het gebruik van computers tijdens het grootschalig toetsen is een complexe zaak en een faculteitsbrede invoering is een uitdagende onderneming. Veel aspecten moeten overwogen worden voordat COT effectief en efficiënt kan worden ingebed in het curriculum.

\section{Tip 1 - Maak het belang van COT duidelijk}

Het is belangrijk vast te stellen waarom COT voordelen kan bieden voor de opleiding. Implementatie van COT vraagt een investering in zowel technologie als mensen. Veel individuele docenten zijn niet in de positie deze investering te doen. Er is een plan nodig dat op het bureau van de beslissingsgerechtigde managers moet komen. Overtuigende argumenten zijn nodig voor de fundering van dit plan. Welke voordelen kunnen genoemd worden?

Computerondersteunde toetsing kan onafhankelijk van plaats en tijd plaatsvinden. Het biedt de studenten de mogelijkheid hun eigen kennisniveau te toetsen op een zelf geselecteerd moment. Daarnaast kunnen studenten vanuit andere locaties (bijvoorbeeld affiliatieziekenhuizen) worden getoetst. Een andere reden om COT te gebruiken is de automatische berekening van resultaten aan het einde van een examen. Het gebruik van een vragenbank met voldoende evaluatiemogelijkheden kan enerzijds de efficiëntie van het toetsproces verbeteren en anderzijds de kwaliteit van onderwijs en de validiteit van toetsen in het curriculum laten toenemen. Andere voordelen zijn al genoemd in de inleiding.

Essentieel in het gebruik van COT is het onderscheid tussen formatief en summatief toetsen. Indien COT gebruikt wordt voor zelfevaluatie (formatief), dan kunnen vragen van eerdere examens hergebruikt worden en kan de gegeven feedback het leerproces optimaliseren. In deze situatie speelt het beveiligingsaspect geen rol en studenten kunnen deze kennistoetsen en quizzes overal doen. Frequente formatieve evaluatie van de studievoortgang kan gemakkelijk worden uitgevoerd met computers. Bij het gebruik van COT voor summatieve toetsing komt wel veel meer kijken, aangezien de toets rechtsgeldig is en er dus hoge eisen aan worden gesteld. In diverse tips in dit artikel wordt verder ingegaan op aspecten die hierbij van belang zijn.

\section{Tip 2 - Gebruik een itembank}

Veel toetsen die op papier worden afgenomen worden ontworpen in de laatste weken voorafgaand aan de examens. Bij geïntegreerde cursussen zijn het vaak meerdere docenten die conceptvragen aanleveren. Het bezwaar bij deze procedure is dat de toetskwaliteit nogal uiteen kan lopen indien er geen gebruik gemaakt wordt van documentatie van vorige toetsen, als die al bestaat.

De computer is een goed instrument, niet alleen om toetsen aan te bieden, maar ook om items te beheren en toetsen te genereren. ${ }^{17}$ Een itembank met een goed doordachte blauwdruk van onderwerpen die alle essentiële elementen bevat kan de inhoudelijke kwaliteit van de toets aanzienlijk doen toenemen. Consistentie van gelijksoortige toetsen door de tijd heen is met name bruikbaar bij resultaatgericht 
onderwijs met specifieke doelen. Vanuit een dergelijke itembank, waarbij de computer erg behulpzaam kan zijn, kunnen niet alleen bepaalde vragen op een later tijdstip worden hergebruikt, maar is ook multidisciplinair tentamineren mogelijk. Door statistieken toe te voegen aan eerder gebruikte items kan de kwaliteit van de vragen en de gehele toets worden bijgehouden en zo nodig worden verbeterd. Om te kunnen komen tot een goed uitgebalanceerde toets zullen de items in de itembank aan de hand van labels met relevante karakteristieken geclassificeerd moeten worden. Labels met klinische vragen kunnen refereren aan a) discipline, b) stadium van de klinische verschijnselen of kenmerken die gevraagd worden zoals: diagnose, onderzoek, behandeling of klachten of aan c) relevantie, significantie of belangrijkheid van het gevraagde (moet dit onderwerp opgenomen worden in elke test of alleen in sommige?).

Er bestaan verschillende systemen voor itembanken, gericht op COT. Question Mark Perception (QMP), EGEL en TestVision zijn voorbeelden die ook in Nederland gebruikt worden. Virtuele elektronische leeromgevingen, zoals Blackboard, hebben ook faciliteiten voor online toetsing, maar hebben vaak geen itembankfaciliteiten. We adviseren medische faculteiten ten zeerste aan te kiezen voor een erkend toetssysteem en hiermee ervaring op te bouwen.

Tip 3 - Zorg voor goede computervoorzieningen en infrastructuur

COT vraagt om adequate computerfaciliteiten. Veel onderwijsinstituten hebben computerruimten voor studenten, maar vaak zijn deze ruimten niet ontworpen met het oog op toetsing. Voor toetsing is een toereikend aantal individuele werkplekken nodig die voldoende van elkaar zijn verwijderd om afkijken te voorkomen. De werkstations moeten bij voor- keur opgenomen zijn in een beveiligd netwerk met centrale opslag van gegevens en back-up faciliteiten. Het is niet acceptabel dat tijdens een toets het computersysteem uitvalt, al is het maar voor enkele minuten. Vanuit een centraal netwerksysteem kunnen de werkstations gecontroleerd en beheerd worden. Het grootste probleem dat opleidingen tegenkomen is het aantal benodigde computers, vooral als het om summatieve toetsing gaat. Het is niet aantrekkelijk voor slechts enkele toetsen per jaar toch honderden computers te moeten aanschaffen. Er zijn echter wel oplossingen voor dit probleem.

Ten eerste moet de vraag gesteld worden of massale toetsing noodzakelijk is. Als het instituut beschikt over een vragenbank met veel vragen van goede kwaliteit, dan is het zeer wel mogelijk in kleine groepen of zelfs individueel te toetsen. Als de toetsen op de juiste manier uit de vragenbank worden 'getrokken', dan moet ervan uitgegaan kunnen worden dat de toetsen gelijkwaardig zijn.

Ten tweede kunnen de studenten de toets afnemen in 'shifts'. ${ }^{18}$ De test wordt dan afgenomen in twee groepen die aansluitend (zonder onderling contact) de toetszaal betreden; op deze wijze kan worden volstaan met de helft van het aantal computers!

Ten derde zou de toets op meerdere locaties kunnen worden afgenomen, zolang deze locaties maar via het netwerk verbonden zijn. Zo kunnen zelfs computerruimten die niet voor onderwijs bedoeld waren, worden gebruikt. Schuwirth beschrijft deze mogelijkheid voor toetsing in het kader van medische probleemoplossing tijdens de coassistentschappen. ${ }^{19}$

Ten vierde kan in combinatie met een draadloos netwerk, gebruik gemaakt worden van laptops op plaatsen waar helemaal geen computerfaciliteiten aanwezig zijn. De laptops kunnen voor toetsdoelein- 
den worden aangeschaft en beheerd, maar de student kan ook zijn eigen laptop gebruiken. In dat laatste geval moet wel extra aandacht worden besteed aan de beveiliging. In enkele gevallen zou zelfs getoetst kunnen worden op andere draagbare apparatuur, zoals PDA's.

Ten slotte kan overwogen worden samen met andere opleidingen of faculteiten over te gaan tot een centrale computervoorziening voor gezamenlijk gebruik.

Zodra COT met enige regelmaat wordt toegepast in het curriculum, is het aan te bevelen een ondersteunend team aan te stellen. Dit team moet er niet alleen voor zorgen dat de verschillende toetsen op de juiste tijd en op de juiste locatie beschikbaar zijn, maar heeft ook de zorg voor het veiligstellen van de resultaten en voor het onderhoud van het systeem. Een dergelijk team moet bij voorkeur multidisciplinair van aard zijn, met experts vanuit onderwijstechnologie, IT-ontwikkeling, IT-infrastructuur en beveiliging. De medisch docenten zijn de experts op het gebied van de inhoud van de toets.

\section{Tip 4 - Benut de unieke mogelijk- heden van computerondersteunde toetsing}

COT verschilt in grote lijnen op twee manieren van een toets op papier: a) de manier waarop het cognitieve processen bij de student stimuleert en b) hoe met de verkregen informatie omgegaan kan worden.

Cognitieve mogelijkheden van COT, die minder goed of helemaal niet mogelijk zijn op papier, zijn vooral het gebruik van vragen met al dan niet bewegend beeld (bijvoorbeeld echografie of CT-beelden), het gebruik van geluidsfragmenten (bijvoorbeeld het herkennen van hart- of longgeluiden) en het stellen van vragen over situaties die tijdafhankelijk zijn en veranderen door de invoer van de student (zoals patiëntsimulaties).
Wat betreft het omgaan met informatieaspecten rondom de toets doelen we onder andere op de mogelijkheid sequentieel of adaptief te toetsen. Een voorbeeld van sequentiële toetsing is het toetsen van een groep studenten met een relatief korte toets. Iedereen die duidelijk slaagt of duidelijk zakt voor de toets, is klaar. De studenten die echter net rondom de cesuur scoren, krijgen een aanvullende toets om betrouwbaarder te kunnen bepalen wie er moet slagen en wie er moet zakken. Adaptieve toetsing houdt in dat studenten onderling andere vragen krijgen voorgeschoteld, afhankelijk van hun eigen niveau, dat vooraf is bepaald door de beantwoording van eerdere vragen. Deze manier van toetsen is vooral geschikt voor formatieve toetsing. Beginnende of wat zwakkere studenten willen graag oefenen met makkelijke vragen, terwijl de betere of gevorderde student graag moeilijkere vragen krijgt aangeboden. Andere aspecten betreffen de mogelijkheid gebruik te maken van vragenbanken, automatische scoreberekening en psychometrische analyses van de toets. Deze aspecten komen terug in de andere tips in dit artikel.

\section{Tip 5 - Bepaal het vraagtype}

Het meest eenvoudige vraagtype is de gesloten vraag uit de categorie meerkeuzevragen, met een aantal alternatieven variërend van 1 tot 5 . Gesloten vragen kunnen door het toetssysteem automatisch gescoord worden. Andere typen gesloten vragen zijn bijvoorbeeld toetsen waarin teksten aan plaatjes moeten worden gekoppeld (matching), en de zogeheten 'Extended matching'-vragen waarbij de student uit een lange lijst van alternatieven kan kiezen. ${ }^{20} \mathrm{Bij}$ 'Comprehensive Integrative Puzzle'-toetsen koppelt de student diagnostische categorieën aan klinische scenario's. ${ }^{21}$ Bij 'Script Concordance'-toetsen wordt de student gevraagd een 
inschatting te geven van een verandering in de diagnose, nadat specifieke nieuwe diagnostische informatie is opgevoerd. ${ }^{22}$ Beide type koppeltoetsen zijn eerder uitgevoerd met computers. Bij gebruik van 'long menu'-vragen, waarbij een groot aantal alternatieven wordt aangeboden in een lange lijst, kan de student een door de computer geconstrueerd antwoord invoeren. ${ }^{23} \mathrm{Bij}$ 'open eind'-vragen moet de student zelf een antwoord intypen.

Bij computerondersteunde toetsen die gebruik maken van open vragen moeten alsnog alle vragen stuk voor stuk beoordeeld worden door een inhoudelijke expert. Het lijkt alsof er daardoor geen voordelen meer zijn ten opzichte van een toets op papier, maar er zijn er toch enkele. Ten eerste worden onleesbare handschriften voorkomen, wat het nakijken vereenvoudigt. Ten tweede wordt een grote hoeveelheid papierwerk vermeden. Het nakijken kan plaatsvinden via internet, wat nakijken mogelijk maakt op elk gewenste plaats en tijdstip. Tenslotte kunnen beoordelingen per vraag via de computer meteen worden verwerkt tot een eindscore en worden opgenomen in de psychometrische analyse van de toets.

Het toepassen van verschillende vraagtypen in één toets is in principe geen probleem; er is immers geen enkel vraagtype intrinsiek beter of slechter dan een ander type. ${ }^{24}$ Vraagtypen moeten wel afgestemd zijn op de doelen van de toets. Om de productie van vragen door diverse docenten in de hand te houden is het wel aan te bevelen slechts een beperkt aantal typen toe te staan. Dit zal trouwens ook voor de student een duidelijker en rustiger beeld geven in de toets.

Tip 6 - Begin klein, maar denk groot

Een eerste toets op de computer is snel en gemakkelijk in elkaar te zetten. De meeste elektronische leeromgevingen bieden de mogelijkheid studenten te toetsen, zo niet dan vinden docenten wel een toetsprogramma ergens op het internet. Dergelijke ad hoc oplossingen zijn meestal niet toereikend voor het gebruik in een hele organisatie. Zodra het gebruik van digitale toetsing toeneemt in de organisatie kunnen eerder gemaakte keuzes het succes hiervan beïnvloeden.

Schaalbaarheid van toetssystemen en andere softwarecomponenten zijn belangrijk. Wellicht moeten in de toekomst de studenten longitudinaal in hun opleiding vervolgd kunnen worden. Denk na over de wijze waarop resultaten van toetsing geïntegreerd kunnen worden in andere informatiesystemen zoals cijferadministratieen inschrijfsystemen voor tentamens. Bedenk ook dat gekozen systemen met de tijd mee moeten. Een toetssysteem waarvan niet regelmatig updates worden uitgebracht wordt al snel obsoleet en zal problemen geven bij het gebruik en bij de integratie met andere systemen. Daarom is het belangrijk te kiezen voor een toetssysteem met een open datastructuur, zodat de door de organisatie opgebouwde data zoals vragen, tentamens en resultaten, eventueel naar een ander softwaresysteem kunnen worden overgezet. Behalve op de functionaliteit van het gekozen toetssysteem, moet dus ook gelet worden op de manier waarop de data in het systeem worden opgeslagen. Dit betekent dat de voor het toetssysteem gebruikte database ook gelezen moet kunnen worden door andere - niet door dezelfde leverancier geleverde - software.

\section{Tip 7 - Beknibbel niet op beveiliging}

Toetsing bepaalt het werktempo van studenten. Studenten doen er alles aan om hun volgende tentamen te halen. De meeste studenten zullen er zelfs voor studeren. Maar het kan ook anders. De database met tentamenvragen bevat zeer waardevolle in- 
formatie voor studenten; er zal dus voor gezorgd moeten worden dat onbevoegden deze database niet kunnen raadplegen. Laat de studenten dus niet te dicht bij deze waardevolle informatie komen. Onderschat hun digitale capaciteiten niet!

Er komt echter een moment dat de studenten zeer dicht bij de opgeslagen tentamenvragen komen en dat is het moment waarop de digitale toets wordt afgenomen. Dit is een kwetsbaar moment. Voor digitale toetsen worden vaak Pc's van de instelling gebruikt. Een bekende methode voor digitale diefstal is het door een student manipuleren van de Pc's waardoor een toets al voor afname digitaal verstuurd wordt naar een plek waar alleen die student bij kan komen. Let ook op de manier waarop de toetssoftware een verbinding legt met de centrale database waar de tentamenvragen zich bevinden en zorg er voor dat studenten er in geen geval achter komen waar deze database zich werkelijk bevindt.

Een ander aspect is dat studenten tijdens het maken van een digitale toets de antwoorden op de vragen niet elders op internet kunnen opzoeken, tenzij dit bewust wordt toegestaan. Hiervoor moeten maatregelen getroffen worden, waardoor studenten tijdens het examen geen andere applicaties behalve de toetssoftware kunnen opstarten. Het kan niet zo zijn dat studenten slagen voor de toets met het bij elkaar 'Google-en' van de antwoorden.

Een laatste beveiligingsprobleem is de authenticatie. Tijdens het digitale examen zijn twee entiteiten belangrijk; het tentamen zelf en de student die het tentamen aflegt. Het tentamen wordt bepaald door de docent, maar wie bepaalt de identiteit van de student? Hoe weet je dat de juiste student de toets doet? Surveillanten moeten dus in staat zijn om, net als bij papieren tentamens, de identiteit van studenten te controleren en te vergelijken met de naam waaronder bij het tentamen is ingelogd.
Een vaak genoemd nadeel van digitale examens is dat studenten gemakkelijker mee kunnen kijken op computerschermen van hun collega's. Dit nadeel wordt weer ondervangen door het feit dat het met digitale toetsen veel gemakkelijker is de vragen te randomiseren, waardoor het afkijken bemoeilijkt wordt. ${ }^{25}$

Toetsing via het internet geeft nog meer beveiligingsproblemen. Een oplossing zou surveillance via webcamera's kunnen zijn, evenals het verplicht meerdere keren intoetsen van wachtwoorden. Misschien dat deze methoden iets helpen voor een juiste identificatie van personen, maar het blijft een niet waterdicht systeem, waardoor toetsing via het internet zonder persoonlijke surveillance voorlopig nog geen bruikbaar alternatief lijkt voor summatieve toetsing.

\section{Tip 8 - Zorg ervoor dat de techniek werkt, maar vertrouw daar niet blindelings op}

Technische problemen zijn al vervelend tijdens het volgen van een college of een E-learningmodule maar helemaal desastreus tijdens een summatieve digitale toets. Helaas is er nog geen softwareprogramma gemaakt zonder fouten. Om een goede digitale toetsing te kunnen garanderen, moet deze service goed ingebed zijn in de organisatie. Ter voorkoming van schade door uitval van softwarecomponenten, moet de toetssoftware elke handeling van de student direct opslaan in de centrale database. Hierdoor kan de student na een computercrash altijd weer op een andere computer verder werken. Zorg ervoor dat in extreme noodsituaties altijd teruggevallen kan worden op een papieren versie. ${ }^{26-28}$

\section{Tip 9 - Informeer en instrueer de studenten}

Zoals bij elk examen moeten studenten goed geïnformeerd worden over de plaats, 
omstandigheden en regels tijdens een examen. Tijdens het maken van examens moet de student zich alleen bezig hoeven te houden met het beantwoorden van de gegeven vragen of probleemstellingen. Het gebruik van een computer bij een examen kan dit verstoren. Bedenk dat studenten toch al gestresst zijn en er niet mee geholpen zijn computerprobleempjes te moeten oplossen of een ingewikkelde besturing van een toetsprogramma te moeten doorgronden. Daarom is het van belang dat studenten, voordat ze een summatief digitaal examen afleggen, al bekend zijn met de toetssoftware, zodat de bediening daarvan geen problemen geeft tijdens het digitale examen. Gebruik hiervoor proeftoetsen. De studenten zullen dit zien als een service van de docent, terwijl het van belang is de studenten te trainen in het gebruiken van de toetssoftware.

Maar een digitale toets gaat dan nog niet vanzelf. Docenten en surveillance blijven nodig om de toetsprocedure uit te leggen en ondersteuning te bieden bij specifieke vragen van studenten.

\section{Tip 10 - Geef feedback over de resultaten}

Bij voorkeur leren studenten ook van de resultaten van hun examens. Met COT is dit goed te realiseren. Bij formatieve toetsen is directe en inhoudelijke feedback mogelijk. Met het geven van feedback bij summatieve toetsen moet gewacht worden tot iedereen het examen heeft afgesloten; dit om het te vroeg vrijgeven van de goede antwoorden te voorkomen. In principe kan de score meteen na het examen worden meegedeeld aan de student. De score in vergelijking met de groepsresultaten is ook nuttige feedback. Desgewenst kan ook gewacht worden met het direct geven van de scores. De docent kan eerst de toetsresultaten nakijken en beoordelen of vraagscores op basis van statistische analyses moeten worden aangepast. Daarna kan de definitieve score worden vastgesteld en aan de studenten worden meegedeeld.

Als feedback kan ook een samenvatting van de geanalyseerde toetsresultaten worden gegeven met adviezen voor verdere bestudering van literatuur.

\section{Tip 11 - Train de docent}

Onderschat niet de ICT-vaardigheden die nodig zijn om een digitale toets te maken en hoeveel moeite dat de docent kan kosten. ${ }^{29}$ Drukbezette docenten willen op een gemakkelijke manier vertrouwd raken met COT. In een instructiemiddag kunnen docenten enthousiast worden gemaakt over de mogelijkheden van COT. In een korte workshop kunnen ze meteen hun eigen vragen invoeren; met behulp van stap-voor-stap instructies voor het samenstellen en afnemen van examens raken ze snel vertrouwd met de methode. ${ }^{30}$ Een goed ondersteuningsteam, dat vragen beantwoordt en hulp biedt aan docenten, is hierbij onontbeerlijk.

\section{Tip 12 - Evalueer de examens}

Met COT kunnen de resultaten van de studenten efficiënt worden beheerd. Na de toets kunnen snel kwantitatieve en kwalitatieve gegevens over de toets worden verkregen. Dit betreft zowel de meningen van de studenten over het examen, als een psychometrische analyse van het examen. Wanneer examens individueel worden afgenomen met verschillende, uniek samengestelde examens per student, kunnen psychometrische gegevens pas na het afnemen van voldoende examens worden verkregen. Opmerkingen van studenten over de vragen zijn meestal waardevol en kunnen bijdragen aan het verbeteren van de vragen.

Door na het examen kritisch naar de vraagscores te kijken, kan aan afwijkend beantwoorde vragen een aangepast gewicht worden gegeven in de eindscore. Als 
geheel geven de scores op de beantwoorde vragen inzicht in de kennis van de studenten en daarmee indirect een beeld van het effect van het aangeboden onderwijs en de vaardigheid van de docent in het maken van vragen.

\section{Conclusie}

Computerondersteunde toetsing biedt een scala aan voordelen: plaats-onafhankelijke formatieve toetsing, gebruik van multimedia, automatische verwerking en analyse van resultaten, en het mogelijk hergebruik van vragen.

Voordat COT succesvol kan worden ingevoerd moet echter een aantal zaken worden bekeken. Summatieve computerondersteunde toetsen vragen soms randvoorwaarden die lastiger zijn dan bij een toets op papier. Het doel en de beoogde efficiencyverbetering en de kosten moeten daarom zorgvuldig worden overwogen voordat COT wordt ingevoerd. Gezien de keuze uit een breed scala aan softwareprogramma's, zal een instituut ten aanzien van de genoemde tips eerst prioriteiten moeten stellen, om vervolgens een team van experts te laten meedenken over de keuze voor een bepaald systeem. Een ondersteunend COT-team is noodzakelijk om COT goed te integreren in het onderwijs, de logistiek te begeleiden en om de techniek te onderhouden.

\section{Dankwoord}

De auteurs danken Elize Berg, studente geneeskunde bij het UMC Utrecht, voor het beschikbaar stellen van een recent rapport over COT en Ali Leijen voor het becommentariëren van de tekst.

\section{Literatuur}

1. Kulik JA, Kulik CC, \& Cohen PA. Effectiveness of Computer Based College Teaching: A meta analysis of findings'; Rev Educ Res 1980;50(4): 525-544.

2. Sargeant JM 2005 Medical education for rural areas: Opportunities and challenges for informa- tion and communications technologies. J Postgrad Med [serial online] (accessed 14 April 2008) 51:3017. Available at: http://www.jpgmonline.com/text. asp?2005/51/4/301/19244.

3. Hayes KA, Lehmann CU. The interactive patient: a multimedia interactive educational tool on the world wide web. MD Comput 1996;13:330-4.

4. Grunewald M, Heckemann RA, Wagner M, Bautz WA, Greess H. ELERA: A WWW Application for evaluating and developing radiologic skills and knowledge. Acad Radiol 2004;11:1381-8.

5. Kronz JD, Silberman MA, Allsbrook WC, Epstein J. A web-based tutorial improves practicing pathologists' Gleason grading of images of prostrate carcinoma specimens obtained by needle biopsy: a validation of a new medical education paradigm. Cancer 2000;89:1818-23.

6. Cantillon P, Irish B, Sales D. Using computers for assessment in medicine. BMJ 2004;329:606-609.

7. Peterson MW, Gordon J, Elliott S, Kreiter C. Computer-based testing: initial report of extensive use in a medical school curriculum. Teach Learn Med. Winter 2004;16(1):51-9.

8. Hulsman RL, Mollema ED, Hoos AM, de Haes JCJM, Donnison-Speijer JD. Assessment of medical communication skills by computer: assessment method and student experiences. Med Educ 2004;38:813-824.

9. Kennedy G, Gray K, Tse J. Net Generation" medical students: technological experiences of pre-clinical and clinical students. Med Teach 2008; 30 (1):10-16.

10. Salpeter J,. $21^{\text {st }}$ Century Skills: Will Our Students Be Prepared? 2003. Available at http://www.techlearning.com, (Accessed 14 April 2008)

11. Ogilvie RW, Trusk TC, Blue AV. Students attitudes towards computer testing in a basic science course. Med Educ 1999;33:828-831.

12. Sambell K, Sambell A, and Sexton. Student perceptions of the learning benefits of computer-assisted assessment: a case study in electronic engineering, Chapter 19, 179-192 in Brown S, Race P, and Bull J. (eds) Computer-Assisted Assessment in Higher Education London: Kogan Page/SEDA (1999).

13. King T. Using computer-aided assessment (CAA) for objective testing in higher education: a case study at the University of Plymouth 121-128 in Hart J. Innovations in Computing Teaching SEDA Paper 88, Birmingham: Staff and Educational Development Association (1995).

14. Johnstone. Comments to Senate Committee on Education Electronic Assessment Delivery (2006). Available at: http://www.senate.state.tx.us/75r/Senate/commit/c530/handouts06/100406.c530.Johnston e_Comments.pdf (Accessed 14 April 2008).

15. Doukas N, Andreatos A. Advancing electronic assessment. International Journal of Computers, Communications and Control 2007;2(1):56-65.

16. Bull J and Collins C. The use of computer-assisted assessment in engineering: some results from the 
CAA national survey conducted in 1999. International Journal of Electronic Engineering Education 2002;39/2: Accessed 15 April 2008, available at http://findarticles.com/p/articles/mi qa3792/is /ai n9070277.

17. De Jong PGM, Bloemendaal PM, Van Leeuwen T. 1998. Experiences with a central item bank for computer-based testing. In: The Eighth International Ottawa Conference on Medical Education and Assessment Proceedings Melnick DE (eds), vol 1. Philadelphia (USA), 2000:151-4.

18. Kreiter C, Peterson MW, Ferguson K, Elliott S. The effects of testing in shifts on a clinical in-course computerized exam. Med Educ 2003;37:202-04.

19. Schuwirth LWT. An approach to the assessment of medical problem solving: computerized case-based testing. PhD dissertation, Maastricht University (1998).

20. Case SM, Swanson DB. Extended-matching items: a practical alternative to free-response questions. Teaching and Learn in Med 1993;5(2):107-115.

21. Ber R. The CIP (Comprehensive integrative puzzle) assessment method. Medical Teacher 2003;25(2):171-176.

22. Sibert L, Darmoni SJ, Dahamna B, Weber J, Charlin B. Online clinical reasoning assessment with the Script Concordance test: a feasibility study. BMC Med Inform Decis Mak 2005; Jun 20 5:18.

23. Schuwirth LWT, Van der Vleuten CPM, Stoffels HEHJ and Peperkamp AGW. Computerised longmenu questions as an alternative to open-ended questions in computerised assessment. Med Educ 1996;30:50-55.

24. Perkin M. Validating Formative and Summative Assessment, Sta and Educational Development Series 55-62. Kogan Page (1999).

25. Rawles S, Joy M \& Evans M. Computer-Assisted Assessment in Computer Science: Issues and Software, Research Report 387, Department of Computer Science, University of Warwick, Coventry. Warren (2002). Available at http://www.ics.heacademy.ac.uk/ (Accessed 14 April 2008).

26. Brown S, Race P \& Bull J. Computer-assissted assessment in Higher Education. London: SEDA and Kogan Page (1999).

27. Bull J, McKenna C. Testing Times (1991), 1(1). Available at; http://www.caacentre.ac.uk/dldocs/ NEWSLETTER1.pdf (Accessed 14 April 2008).
28. Bull J, McKenna C. Blueprint for Computer-assissted assessment. London: Routledge Falmer (2003).

29. Singer J, Marx RW, Krajcik J and Clay-Chambers J. Constructing extended inquiry projects: Curriculum materials for science education reform. Educ Psychol 2000;35(3): 165-178.

30. Margerum-Leys J \& Marx R.Teacher knowledge of educational technology: A study of student teacher/mentor teacher pairs. Manchester, New Hampshire: J of Educ Comp Res 2002;26(4):427462

De auteurs: ${ }^{*}$

Mw. drs. W.P.M. Hols-Elders is programmaleider bij het Expertisecentrum, directie Onderwijs en Opleidingen van het Universitair Medisch Centrum Utrecht.

Drs. P.M. Bloemendaal is universitair hoofddocent bij de afdeling Heelkunde van het Leids Universitair Medisch Centrum.

Mw. drs. N.R. Bos is ICT \& Onderwijs consultant bij de afdeling Onderwijs en Studentenzaken van het Academisch Medisch Centrum, Universiteit van Amsterdam. Dr. M.J. Quaak is onderwijskundig adviseur bij het Expertisecentrum, directie Onderwijs en Opleidingen van het Universitair Medisch Centrum Utrecht.

Drs. R. Sijstermans is coördinator ICT \& Onderwijs bij de afdeling Onderwijs \& Studentenzaken van het Academisch Medisch Centrum, Universiteit van Amsterdam. Dr. Ir. P.G.M. de Jong is stafadviseur E-learning aan het Onderwijscentrum van het Leids Universitair Medisch Centrum en voormalig voorzitter van de NVMO werkgroep E-learning.

* Alle auteurs zijn lid van de werkgroep E-learning van de Nederlandse Vereniging voor Medisch Onderwijs (NVMO).

\section{Correspondentieadres:}

Drs. Willie P. M. Hols-Elders, Expertisecentrum, directie Onderwijs en Opleidingen, UMC Utrecht, postbus 85090, HB4.05, 3508 AB Utrecht.

Email:w.p.m.hols@umcutrecht.nl

Belangenconflict: geen gemeld

Financiële ondersteuning: geen gemeld

\section{Summary}

The use of computers in education in general and in medical education in particular is nowadays well established, but the use of computer-based assessment (CBA) in higher education lags behind. In this article we explore the reasons for this situation and provide tips for teachers to guide the introduction of CBA, based on our experiences. Attention is given to benefits and drawbacks of CBA hardware solutions, the choice of software, types of test questions, security, instructing students and teachers and evaluation. (Hols-Elders WPM, Bloemendaal PM, Bos NR, Quaak MJ, Sijstermans R, Jong PGM de. Twelve tips for computer-based testing in medical education. Dutch Journal of Medical Education 2009;28(1):4-12.) 